\title{
ДИАГНОЗ В ОДНОМЕРНОЙ ПСИХИАТРИИ
}

\section{Елена Николаевна Давтян}

Российский государственный педагогический университет им. А.И. Гериена, 191186, г. Санкт-Петербург, наб. реки Мойки, 48, e-mail: elena.davtian@gmail.com

\section{Реферат}

На основании анализа смыслового наполнения слова «диагноз» в общей медицине и в психиатрии автор приходит в выводу, что из всех функций диагноза (медицинской, социальной, экономической и статистической) современный психиатрический диагноз обладает только последними двумя - экономической и статистической. Клиническая (медицинская) составляющая из диагноза исчезает. Анализируются истоки такого положения дел. Обосновывается положение о том, что статистический язык операциональной психиатрии - это язык-пиджин, который привёл к формированию одномерной психиатрии.

Ключевые слова: психиатрия, диагноз, классификации, МКБ-10, МКБ-11, пиджин, операциональный.

\section{DIAGNOSIS IN THE ONE-DIMENSIONAL PSYCHIATRY}

\section{Elena N. Davtian}

Russian State Pedagogical University named after A.I. Herzen, 191186, St. Petersburg, emb. of the Moika river, 48, e-mail: elena.davtian@gmail.com

\section{Abstract}

Based on the analysis of the semantic content of the word "diagnosis" in general medicine and psychiatry, the author comes to the conclusion that of all the functions of diagnosis (medical, social, economic and statistical), modern psychiatric diagnosis has only the last two ones - economic and statistical. The clinical (medical) component of the diagnosis disappears. The origins of this state of things are analyzed. The article substantiates the position that the statistical language of operational psychiatry is a kind of pidgin languages, which led to the one-dimensional psychiatry.

Keywords: psychiatry, diagnosis, classification, ICD-10, ICD-11, pidgin, operational.

$\mathrm{H}$ аше время характеризуется появлением большого количества профессиональных слов с неясным статусом и, как следствие, с не вполне определённым значением. Это касается как прямой «кальки» с английского языка, которая в русскоязычной среде воспринимается весьма неоднозначно, а часто и просто двусмысленно (например, «начинающие карьеру психиатры», шкалы «удовлетворённости» и «счастливости» и т.д.), так и привычных профессиональных слов, меняющих своё содержание в зависимости от времени и от места их употребления.
Автору статьи неизвестна ни одна научная дисциплина, в которой профессиональные термины менялись бы с такой скоростью, как в психиатрии, и зависели бы от самых разнообразных, часто не имеющих отношения к непосредственной профессиональной деятельности, причин. К числу таковых, прежде всего, относятся постоянно «совершенствующиеся» статистические классификации и давление сообществ потребителей психиатрических услуг, которые под флагом дестигматизации получили право менять язык психиатрии по своему усмотрению.

Всё это уже привело к явлению массовой детерминологизации психиатрических понятий, когда бывшие ранее однозначными термины вошли в обыденную речь и стали неопределёнными словами, не имеющими истории употребления. Каждый носитель языка теперь вкладывает в них тот смысл, который он вложить в них хочет (например, термины депрессия, аутизм, паническая атака, биполярное аффективное расстройство).

Психиатры оказались в сложной ситуации, так как существующая «терминологическая чехарда» запутывает самих профессионалов. Согласно общей терминологии (науке о терминах), замена даже неудачных, но хорошо внедрённых терминов связана с ломкой устоявшейся системы и ненужным переучиванием [1]. В ситуации постоянных терминологических изменений (и, как следствие, непрерывной «ломки» профессиональной системы с необходимостью многократного «переучивания») для того, чтобы просто понять профессиональный текст, психиатру необходимо приложить немало усилий по прояснению смысла слов, так как приходится учитывать массу факторов: «Кто писал? В какое время? Какая была принята в тот момент номенклатура? Какой смысл исследователи вкладывали в тот или иной термин? Как это значение слова соотносится с классическими психиатрическими текстами и тем, что мы наблюдаем в клинике?» и т.д.

Нам представляется, что не избежало участи разночтений в психиатрии и такое традиционное врачебное слово, как «диагноз». Если обратиться к толковым и медицинским словарям, то, как правило, определение медицинского диагноза производится через понятие «болезни» [2]. Так, в словаре иностранных слов А.Н. Чудинова диагноз определяется как «определение болезни по её обнаружившимся признакам». 
Диагностика как «определение болезни» звучит и в основных требованиях к современной формулировке диагноза: диагноз должен быть нозологическим, соответствовать принятой международной номенклатуре, быть развёрнутым (содержать форму заболевания, тип течения, степень активности процесса и пр.), быть этиологическим и патогенетическим [3]. Кроме того, сам по себе диагноз обладает разнообразными функциями: медицинской, социальной, экономической и статистической. Медицинскую и социальную функции диагноза всегда считают приоритетными по отношению к экономической и статистической.

Общепринятой международной классификацией служит Международная классификация болезней (МКБ), в настоящее время - 10-го пересмотра ${ }^{1}$. Однако в психиатрическом разделе классификации понятие «болезнь» отсутствует. Для определения психопатологических состояний использовано слово «расстройство». При этом ясного определения, чем отличается «расстройство» от привычных в классической психиатрии болезней (невроза, шизофрении) или патологических состояний (психопатии, малоумия), разработчики МКБ не дают, хотя и указывают, что расстройство «подразумевает под собой существование клинически распознаваемых совокупностей симптомов или отклонений в поведении» [4] (дискуссия на эту тему недавно разгорелась в отечественной печати $[5,6])$.

Однако если нет заболеваний, а существуют только «совокупности симптомов», то нет и форм болезней и типов течения. По-видимому, с этим связано исчезновение из МКБ-11, например, клинических форм шизофрении или тенденция к безудержному «укрупнению» ранее разнородных патологических состояний в единые «спектры расстройств» (например, расстройства аутистического или шизофренического спектра). Более того, из всех требований к современной формулировке диагноза (в соответствии с законодательством РФ) психиатрический диагноз, по-видимому, способен полноценно выполнить только одно - соответствие принятой международной номенклатуре.

В этом месте имеет смысл вспомнить, какими бывают и для чего нужны классификации. Классификация - стандартный общенаучный метод организации знания. Классификации выполняют две задачи: (1) надёжно распознавать изучаемую область; (2) заключать в себе максимально полную информацию об объектах изучаемой области [7].

Классификации бывают естественными и искусственными. Естественная классификация возникает на основе наблюдений и является синтезом эмпирических и теоретических представлений. В контексте психиатрии естественными классификациями были классификации различных психиатрических школ в «дооперациональную эпоху», весьма подробно изложенные в известном докладе Э. Стенгеля (1959) [8]. Многообразие школ и несовпадение их взглядов в тот период - обычный и закономерный этап естественного развития научной дисциплины. Следует отметить, что только естественная классификация считается обоснованной типологией и может претендовать на решение содержательных задач и прогнозирование новых результатов [7].

В отличие от естественной, искусственная классификация строится часто на прагматических основаниях и основывается на произвольно выбранных и удобно различимых свойствах объектов. Решить такая классификация способна только первую задачу классификаций - распознавание объектов по их специально отобранным свойствам. Не вызывает сомнений, что в психиатрии такими искусственными классификациями стали МКБ-10 и следующая за ней МКБ-11. Выставленный психиатрический диагноз в соответствии с этими классификациями - не диагноз в привычном клиническом смысле слова. Это узнавание «совокупности симптомов», произведённое по определённым правилам и необходимое для учёта и статистики для нужд управления здравоохранением.

Никто никогда и не скрывал, что именно для этого и разрабатывалась операциональная статистическая классификация: «Результатом диагностического процесса по МКБ-10 является не диагноз в традиционном понимании с полнотой клинического описания, выделением ведущего синдрома и учётом индивидуальных особенностей пациента, а статистически ориентированная констатация диагностических критериев включения и исключения» [9].

В официальной инструкции Министерства здравоохранения РФ по использованию МКБ-10 (утверждена 25 мая 1998 г. №2000/52-98) написано, что «остаётся проблемой сопоставление клинических диагнозов и диагнозов, приведённых в МКБ», что в МКБ «сохранилась тенденция к значительной модернизации диагнозов без учёта клинической практики», что «сложные методические вопросы возникают в отношении терминов, используемых в МКБ» и, наконец, что вряд ли сейчас МКБ «можно рекомендовать в качестве образца терминологии и записей клинических диагнозов».

В подтверждение вышесказанного и без всяких комментариев приведём цитату с официального сайта Всемирной организации здравоохранения (русскоязычная часть, посвящённая МКБ-11): «Критически важный аспект взаимодействия с МКБ состоит в том, что включение или исключение того или иного состояния не является суждением о его обоснованности или об эффективности лечения» [10].

В большинстве стран мира [3, 11] обязанность кодирования клинического диагноза в соответствии со

${ }^{1} \mathrm{~B}$ строгом смысле слова классификацией психиатрический раздел МКБ в настоящее время не является, так как не имеет единого основания для выделения объектов. 
стандартами действующей МКБ возложена на специалистов по медицинской статистике, а не на клиницистов. Среди российских врачей - преподавателей вузов и постдипломного образования - идёт дискуссия о бесперспективности и ненужности обучения врачей несвойственной им функции - функции кодировщиков и статистиков. Задача клинициста - диагностировать и лечить, а современное семейство МКБ в любой врачебной специальности превратилось в большую специализированную область знания, требующую отдельного обучения. Именно с этой «новой» функцией, возложенной в России на клиницистов, связывают значительные расхождения в статистических данных о заболеваемости и смертности как между регионами и субъектами РФ, так и с международными статистическими данными.

В медицинской литературе (как юристами медицинского права, так и врачами других специальностей) активно обсуждается проблема сопоставления клинического диагноза и статистического диагноза МКБ. Кардиологи пишут о проблемах «статистической интерпретации клинических диагнозов», которые есть «во всех странах мира», и предлагают российским клиницистам системы соответствия/согласования клинических терминов с кодами МКБ с рекомендациями, как лучше использовать (или не использовать) отдельные статистические рубрики МКБ в связи с разницей понимания, интерпретаций, школ и традиций [11].

Никаких подобных дискуссий в психиатрической литературе нет, потому что, похоже, психиатрия избавилась от подобного рода проблем. В психиатрии МКБ не стала, как в других врачебных специальностях, языком-посредником - лингва франка международного общения для специалистов разных национальных школ. Принятие новой операциональной парадигмы (МКБ-10) разом отменило все национальные школы, взгляды и теории. У официальной международной психиатрии сегодня есть единственный язык язык операциональной МКБ, и есть единственный диагноз - не привычный клинический (с продромом, дебютом, определённым алгоритмом развития симптомов и синдромов, исходом и пр.), а простой статистический, основанный на конвенциональных («договорных») критериях включения/исключения.

В официальных психиатрических публикациях не принято акцентировать внимание на проблемах, оставшихся после «радикального переворота»:

1) на необходимости разработки глоссариев толковых словарей для используемых терминов, так как «выдернутые» из отменённых теоретических воззрений их авторов термины утратили определённость и стали нуждаться в пояснениях; к слову сказать, начавшаяся в этом отношении работа так и осталась недоделанной - подавляющее большинство использованных в текущей МКБ терминов в глоссариях не содержится;
2) нерешённой остаётся проблема «измерительного инструментария» (медицинских опросных инструментов), ведь для того, чтобы система заработала, необходимо, чтобы опросники на $100 \%$ передавали смыслы, заложенные разработчиками в вопросыстимулы, в головы носителей любого другого языка; эта задача, насколько мы понимаем, вообще невыполнима;

3) крайне дискуссионным представляется объявление критериев включения/исключения операциональными - создатель философии операционализма П. Бриджмен имел в виду под операциями буквальные физические измерения в процессе эксперимента, причём разные способы измерения одного и того же предполагали разные смысловые содержания понятия; возможно в отношении МКБ понятие «операциональный» используется в каком-то другом, неизвестном нам смысле.

И это - далеко не полный перечень возникающих вопросов и проблем.

А вот чем принято гордиться в официальных психиатрических публикациях, так это созданием единого языка для психиатров разных стран (всё та же МКБ, начиная с 10-го пересмотра). Что из себя представляет этот язык? Он обладает рядом специфических особенностей:

- это упрощённое средство коммуникации между психиатрами, говорящими на разных языках;

- не является родным ни для одного из использующих его психиатрических сообществ;

- его словарный запас невелик, бытует он без жёстких правил и отличается высокой гибкостью и крайней изменчивостью.

Лингвисты называют языки с такими характеристиками языками-пиджинами. Обычно такие квази-языки живут недолго, так как предназначены для сугубо утилитарных целей. Однако вполне возможна ситуация, когда со временем подобный язык может стать единственным для его носителей. И тогда в психиатрии наступит что-то похожее на «статистический рай» желаемое единообразие в действиях, диагностических процедурах и головах психиатров.

Казалось бы, что такого особенного в классификациях? В конце концов, они могут быть более или менее удобными для повседневной работы, не более. Однако классификацию, претендующую на право стать единственным языком специальности, нельзя оставлять без внимания. Именно язык категоризирует нашу реальность, и профессиональную реальность в том числе. В конечном итоге статистический язык МКБ как единственный язык психиатрии может привести (привёл?) к одномерной психиатрии. По-видимому, недостаёт только критической массы одномерных психиатров. Впрочем, Герберт Маркузе уже писал об этом в своей известной работе («Одномерный человек», 1964 г.). 


\section{ЛИТЕРАТУРА}

1. Суперанская А.В., Подольская Н.В., Васильева Н.В. Общая терминология: вопросы теории. Отв. ред. Т.Л. Канделаки. Изд. 6-е. М.: Либроком. 2012; 248 с. [Superanskaya A.V., Podol'skaya N.V., Vasil'eva N.V. Obshchaya terminologiya: Voprosy teorii. Otv. red. T.L. Kandelaki. Izd. 6-e. M.: Librokom. 2012; 248 p. (In Russ.)]

2. Словари, энииклопедии. https://www.endic.ru/ozhegov/ Diagnoz-7023.html (дата обращения: 15.01.2021). [Slovari, ehntsiklopedii. https://www.endic.ru/ozhegov/Diagnoz-7023. html (access date: 15.01.2021). (In Russ.)]

3. Зайратьянц О.В., Кактурский Л.В., Мальков П.Г. К формулировке диагноза в соответствии с законодательством Российской Федерации и Международной статистической классификации болезней 10-го пересмотра. Судебная мед. 2015; 1 (4): 14-20. [Zayrat'yants O.V., Kakturskiy L.V., Mal'kov P.G. K formulirovke diagnoza $v$ sootvetstvii $s$ zakonodatel'stvom Rossiyskoy Federatsii i Mezhdunarodnoy statisticheskoy klassifikatsii bolezney 10 -go peresmotra. Sudebnaya meditsina. 2015; 1 (4): 14-20. (In Russ.)] DOI: 10.19048/2411-8729-2015-1-4-14-20.

4. Сарториус Н. Понимание МКБ-10: классификациия психических расстройств. Карманный справочник. К.: Сфера. 2002; 104 c. [Sartorius N. Ponimanie MKB-10: Klassifikatsiya psikhicheskikh rasstroystv. Karmannyy spravochnik. K.: Sfera 2002; 104 p. (In Russ.)]

5. Менделевич В.Д. Что даёт пациенту психиатрический диагноз и обоснован ли тренд на увеличение числа болезней? Неврологич. вестн. 2019; LI (1): 52-54. [Mendelevich V.D. Chto daet patsientu psikhiatricheskiy diagnoz i obosnovan li trend na uvelichenie chisla bolezney? Nevrologicheskiy vestnik. 2019; LI (1): 52-54. (In Russ.)]

6. Носачев Г.Н. Место фейк-диагноза и функционального диагноза в психиатрии (институциональный дискурс). Неврологич. вестн. 2019; LI (2): 101-104. [Nosachev G.N. Mesto feyk-diagnoza i funktsional'nogo diagnoza v psikhiatrii (institutsional'nyy diskurs). Nevrologicheskiy vestnik. 2019; LI (2): 101-104. (In Russ.)]

7. Субботин А.Л., Абушенко В.Л., Бочаров В.А., Эдельман В.А. Классификаиия. Гуманитарный портал. https:// gtmarket.ru/concepts/6879 (дата обращения: 15.01.2021). [Subbotin A.L., Abushenko V.L., Bocharov V.A., Ehdel'man V.A. Klassifikatsiya. Gumanitarnyy portal. https:/gtmarket.ru/ concepts/6879 (access date: 15.01.2021). (In Russ.)]

8. Stengel E. Classification of mental disorders. Bull. World Health Org. 1959; 21: 601-663.

9. Корень Е.В., Татарова И.Н., Марченко А.М. и др. Опыт применения МКБ-10 в российской детской психиатрии в перспективе пересмотра Международной классификации. Социал. и клин. психиатрия. 2009; XIX (4): 34-40. [Koren' E.V., Tatarova I.N., Marchenko A.M. et al. Opyt primeneniya MKB-10 $\mathrm{v}$ rossiyskoy detskoy psikhiatrii $\mathrm{v}$ perspektive peresmotra Mezhdunarodnoy klassifikatsii. Sotsial'naya $i$ klinicheskaya psikhiatriya. 2009; XIX (4): 34-40. (In Russ.)]

10. Официальный сайт ВОЗ, русскоязычная часть. https://www.who.int/ru/news-room/spotlight/international-

classification-of-diseases (дата обращения: 15.01.2021). [Ofitsial'nyy sayt VOZ, russkoyazychnaya chast'. https://www. who.int/ru/news-room/spotlight/international-classification-ofdiseases diseases (access date: 15.01.2021). (In Russ.)]

11. Бойцов С.А., Самородская И.В., Галявич А.С. и др. Статистическая, клиническая и морфологическая классификация ишемической болезни сердца - есть ли возможность объединения? Рос. кардиол. ж. 2017; 3 (143): 63-71. [Boytsov S.A., Samorodskaya I.V., Galyavich A.S. et al. Statisticheskaya, klinicheskaya i morfologicheskaya klassifikatsiya ishemicheskoy bolezni serdtsa - est' li vozmozhnost' ob"edineniya? Rossiyskiy kardiologicheskiy zhurnal. 2017; 3 (143): 63-71. (In Russ.)] DOI: 10.15829/15604071-2017-3-63-71.

Поступила 17.01.2021; принята в печать 01.02.2021. 